\title{
ARTEFATOS DIGITAIS DE REVISTAS MENSAIS BRASILEIRAS, REVISTAS DIGITAIS E A PRESENÇA DO DESIGN NAS EQUIPES EDITORIAIS
}

\author{
Pedro Biz Eschiletti \\ ESDI/UERJ \\ pedrotrg@gmail.com \\ Washington Dias Lessa \\ ESDI/UERJ \\ washington.lessa@gmail.com
}

\begin{abstract}
Resumo: Este artigo tem como objetivo situar a revista digital entre os artefatos digitais publicados por revistas brasileiras, assim como o de avaliar a apresentação das equipes de trabalho respectivas, destacando o designer em suas denominações e funções. Foram escolhidas as 30 revistas com maior circulação mensal no ano 2012-2013 e levantados os artefatos digitais a elas relacionados. Apesar da revista impressa ser o produto principal das editoras, a comunicação com o público é complementada por esses artefatos. A pesquisa foi realizada com base em informações declaradas nos sites das revistas e editoras, nos expedientes e nas lojas de aplicativos para iPad e Android.
\end{abstract}

Palavras-chave: revistas mensais, design, mídias digitais

\begin{abstract}
This article aims to place the digital magazine among artifacts published by the Brazilian magazines, as well as to evaluate the way the workgroups are shown, highlighting the role of the designer in its designations and functions. We chose the 30 magazines with more monthly issues in the period of 2012-2013 and raised the artifacts related to them. In spite of the printed magazine being the main product of the press, the communication with the audience is complemented by these artifacts. The research was made based on information found on magazine and press websites, mastheads and iPad and Android app stores.
\end{abstract}

Keywords: monthly magazines, design, digital media 


\section{INTRODUÇÃO}

Uma revista pode ser compreendida de duas maneiras: como marca e como mídia ${ }^{1}$. Uma não anula a outra. Enquanto marca, a revista envolve uma identidade que diz respeito não apenas a um produto tradicional, originariamente impresso, mas também a ações e a outros artefatos visando um posicionamento no mercado. Vários são os objetivos dessas ações e artefatos: reforçar a identidade da marca, fidelizar e/ou ampliar público, disponibilizar conteúdos complementares, trabalhar de modo coordenado com outras marcas, entre outras estratégias editoriais e mercadológicas. Sendo assim, a revista como marca não difere de qualquer outra marca, senão por sua atuação em mercado editorial específico, regulado segundo parâmetros conceituais, jornalísticos e mercadológicos. Enquanto mídia, a revista caracteriza-se como artefato baseado em uma tecnologia de comunicação.

No caso desta pesquisa, partiu-se de marcas consolidadas a partir de mídias impressas, mas que envolvem mídias digitais. A mudança de meio implica em uma reconfiguração do trabalho, envolvendo diferentes ferramentas, novos conhecimentos e novas categorias profissionais.

O presente artigo teve como objetivo levantar os tipos de artefatos digitais publicados por revistas impressas brasileiras, situar nesse quadro a revista digital, e avaliar a apresentação das equipes respectivas de realização, destacando o design em suas funções e denominações.

\section{REVISTAS E MÍDIAS DIGITAIS}

A revista impressa é um artefato jornalístico caracterizado por uma temática específica, periodicidade expandida (semanal, mensal, ou outra), informações detalhadas, analíticas e interpretativas, "e uma condição material e discursiva específica, que dialoga com o contexto do qual ela é parte constituinte" (TAVARES \& SCHWAAB, 2013, p. 27).

Reúne conteúdos variados sob uma temática específica direcionada a um publico "imaginário padrão, diferente dos leitores das demais publicações" (ARAÚJO, 2013, p. 261). A criação e consolidação de uma revista depende da existência de um nicho social compatível. Corrêa (apud ARAÚJO, 2013, p. 262) relata que a primeira revista feminina brasileira, $O$ Espelho Diamantino, foi lançada no mesmo ano que se ratificou a lei que estendia o direito de alfabetização às mulheres, em 1827.

O editor e pesquisador Sérgio Cohn afirma que na década de 1990 "a plataforma digital começou a ser utilizada como suporte para revistas culturais", trazendo ao mesmo tempo novas possibilidades, mas também desafios. Se por um lado havia uma redução de custos, por outro as revistas "não conseguiram se consolidar como espaço publicitário" (COHN, 2011, p. 241). Cohn percebe duas vertentes em relação ao formato dessas publicações: "as que mantiveram a estrutura das revistas impressas, apenas as adequando ao suporte digital, e as que buscaram utilizar as ferramentas tecnológicas e sociais disponibilizadas por esse novo meio" (id., p. 241). Embora Cohn esteja tratando do caso específico de revistas culturais, sua afirmação é válida também para as demais que até hoje buscam a sustentabilidade

\footnotetext{
${ }^{1}$ Mídia aqui não é entendida como o setor de venda de anúncios das revistas, apenas como o meio de comunicação.
} 
econômica em um meio onde o público está acostumado a acessar conteúdo de maneira gratuita.

As mídias digitais se constituem em um mercado no qual as bases tecnológicas - de hardware e de software - estão em constante transformação. Isso amplia a variedade de artefatos que transmitem informação, contribuindo para a dispersão da mídia. Jenkins afirma que ao mesmo tempo que o conteúdo está convergindo para os meios digitais, as tecnologias que permitem essa comunicação estão divergindo. A previsão de que todas as mídias seriam condensadas em apenas um dispositivo - à qual Jenkins se refere como " falácia da caixa preta" (JENKINS, 2006, loc. 402) - não está se concretizando. O cenário é de cada vez mais artefatos de acesso à informação como tablets, smartphones, e-readers, dispositivos vestíveis (weareable devices), produzidos por inúmeras marcas, que, naturalmente, instituem incompatibilidades tecnológicas entre concorrentes como estratégia de mercado.

Ao contrário da mídia impressa, no meio digital a informação flui dispersa através de diversos artefatos. É o que Jenkins chama de convergência de cultura. Mais do que uma mudança tecnológica assiste-se a uma mudança cultural, orientada pela "cooperação entre múltiplas indústrias da mídia e o comportamento migratório da audiência, que irá a quase qualquer lugar na busca das experiências [...] que quiserem" (JENKINS, 2006, loc. 178²).

Existem inúmeras formas de disponibilizar conteúdo via mídia digital: websites, canais de vídeos, jogos, blogs, redes sociais, entre outras. Para se aproximar de seu público-alvo, editoras disponibilizam em outros artefatos o conteúdo tradicionalmente apresentado pela revista. Observamos tal situação nos portais de conteúdo, que centralizam a presença online da revista-marca. Além do acesso a reportagens é possível assinar a revista, tanto impressa quanto digital, acessar mídias sociais, blogs de especialistas, o canal de vídeo, o canal de jogos, assinar a newsletter; escutar podcasts, baixar aplicativos exclusivos para smartphones etc. O portal da revista Nova Escola, por exemplo, vai além da revista e se propõe a ser um portal de apoio ao professor. Apresenta propostas de planos de aula para disciplinas da educação infantil ao ensino médio, vídeos, jogos, testes. Os portais estão ligados a modelos que se desenvolveram a partir da internet, possuindo estruturas de produção com concepções, métodos de trabalho e profissionais com formações diferentes da editorial.

Desde o lançamento do iPad, em 2010, editoras passaram a produzir versões para tablets de suas revistas, com o conteúdo das edições impressas. O que parece ter sido encontrado com as revistas digitais para tablets foi uma forma de "evoluir" os modelos editorial e econômico que começaram a se formar ainda no século XIX. Como estamos tratando de um mercado recente, os modelos de tablets funcionam em caráter por vezes experimental, considerando que ainda não conseguem cobrir os custos de produção de conteúdo, seja pelo pequeno porém crescente número de leitores, seja pela desconfiança e falta de interesse dos anunciantes. Entretanto, a queda do consumo de revistas impressas nos últimos anos é uma realidade atribuída à migração de leitores para o meio digital, que dispersam-se entre dispositivos e a enorme quantidade de informação acessível ao custo do provedor de internet e da energia elétrica.

\footnotetext{
${ }^{2}$ Referência Kindle e-book. Tradução dos autores.
} 
A tradição de websites de fornecer conteúdo gratuitamente é um dos problemas que editoras vêm enfrentando na reformulação de seus modelos de negócio frente às imposições do mercado digital. Faz-se necessário uma reestruturação organizacional das editoras, inclusive repensando a própria ideia de revista. Para Paulo Lima, publisher das revistas Trip e TPM, os dois títulos são tratados como "uma grande plataforma voltada ao nicho comportamental", sendo "composta pelas duas revistas, dois eventos [...], um programa de TV e programa de rádio" (PARENTE, 2013, p. 16).

\section{DESIGN EDITORIAL E REVISTA}

O papel do designer no processo de produção mensal de uma revista está ligado à conformação das categorias gráfico-editoriais de acordo com os padrões editoriais e o conteúdo das matérias, visando criar mensagens visuais que engajem o público na leitura. Eventualmente designers são responsáveis também pela criação de infográficos, ilustrações e outros elementos gráficos.

Trabalham em conjunto com jornalistas e são peça fundamental na definição gráfica da revista, participando ativamente da edição das imagens, das soluções tipográficas, cromáticas, da elaboração de infográficos de outros elementos visuais que compõem as matérias. Segundo Gruszynski e Calza o design "perpassa as várias fases de produção e exige que os membros da equipe ponderem sobre os recursos verbais e visuais que possam melhor reportar o conteúdo" (GRUSZYNSKI; CALZA, 2013, p. 208). Também reforçam a importância da atividade colaborativa entre jornalistas e designers, afirmando que cabe ao designer ter "bom domínio do jornalismo e ao jornalista/editor reconhecer a importância do design" (id., p. 208).

Segundo Werneck, o trabalho do designer ou editor de arte seria o de "dar a tudo uma identidade (com uma capa - que é a face), para torná-las um conjunto coerente e singular (as páginas - miolo ou corpo), buscando atrair o leitor e ganhar dele a lealdade eterna" (WERNECK et al, 2000, p. 123). No mesmo sentido, Samara afirma que a função do designer editorial é a mesma, independente do meio de publicação: "envolver uma audiência em uma mensagem ou assunto por um período de tempo" (SAMARA, 2005, p. 12). No meio digital esta afirmação não deixa de ser válida, segundo Manoel Lemos, chief digital officer da editora Abril em entrevista para uma edição especial sobre revistas digitais do jornal Meio \& Mensagem: "o maior desafio [das revistas] é o design de [um] produto para gerar experiência" (PARENTE, 2013 , p. 4). Experiência é um termo comum ao meio digital que parece atualizar a ideia de envolvimento com conteúdo. Lemos ainda afirma que "não se trata de adaptar um mesmo produto para uma nova telinha, mas de redesenhá-lo para cada uma das plataformas" (PARENTE, 2013, p. 4), reforçando a posição estratégica do designer na implementação de revistas no meio digital. Cabe ressaltar que, trabalhando com o conceito de experiência do usuário, o designer participa do esforço para mobilizar e envolver a audiência.

\section{UNIVERSO DE ANÁLISE}

Foram escolhidas as 30 revistas com maior circulação mensal no ano 20122013, identificadas em pesquisa do Instituto Verificador de Circulação (IVC). Os números de circulação referem-se apenas às revistas impressas pagas, ou seja, os dados de circulação dos artefatos digitais analisados não estão contabilizados nos 
dados dessa pesquisa. A escolha do índice restringiu a amostra a revistas que teriam maiores condições econômicas de investir em diferentes mídias para se manterem na liderança. Cabe mencionar que esses periódicos não são necessariamente concorrentes. As três primeiras, Nova Escola, Claudia e Superinteressante, por exemplo, são líderes em seus respectivos segmentos temáticos e destinam-se a públicos diferentes.

A partir dessa seleção, a pesquisa sobre os artefatos digitais foi feita com base no que estava declarado nos websites das revistas, websites das editoras, Google Play Store, iTunes Store, redes sociais e nas edições impressas. Em paralelo, buscou-se nos expedientes gerais e das revistas digitais informações sobre a composição das equipes de trabalho destacando a presença do designer.

Tabela 1. Maiores Circulações: revistas mensais. Janeiro a agosto - 2013-2012.

\begin{tabular}{|c|c|c|c|c|}
\hline POS & TítULo & EDITORA & $\begin{array}{l}\text { CIRCULAÇÃO } \\
\text { MÉDIA } \\
\text { JAN A AGO/13 }\end{array}$ & $\begin{array}{l}\text { CIRCULAÇÃO } \\
\text { MÉDIA } \\
\text { JAN A AGO/12 }\end{array}$ \\
\hline 1 & Nova Escola & FVC & 408.182 & 371.335 \\
\hline 2 & Claudia & Abril & 373.431 & 388.276 \\
\hline 3 & Superinteressante & Abril & 312.806 & 320.430 \\
\hline 4 & Seleções Reader's Digest & Reader's Digest & 270.450 & 310.511 \\
\hline 5 & Quatro Rodas & Abril & 233.232 & 237.772 \\
\hline 6 & Saúde & Abril & 213.936 & 205.093 \\
\hline 7 & Boa Forma & Abril & 209.772 & 203.702 \\
\hline 8 & Manequim & Abril & 201.952 & 206.841 \\
\hline 9 & Nova & Abril & 200.122 & 218.472 \\
\hline 10 & Casa Claudia & Abril & 171.620 & 192.818 \\
\hline 11 & Minha Casa & Abril & 166.239 & 185.128 \\
\hline 12 & Marie Claire & Globo & 165.505 & 185.470 \\
\hline 13 & Guia Astral & Alto Astral & 148.633 & 167.070 \\
\hline 14 & Mônica & Panini & 145.326 & 147.226 \\
\hline 15 & Cebolinha & Panini & 133.352 & 141.704 \\
\hline 16 & Você S.A. & Abril & 130.863 & 147.141 \\
\hline 17 & Máxima & Abril & 125.178 & 135.212 \\
\hline 18 & Playboy & Abril & 125.163 & 140.537 \\
\hline 19 & Mundo Estranho & Abril & 122.588 & 122.766 \\
\hline 20 & Casa \& Jardim & Globo & 121.726 & 124.296 \\
\hline 21 & Magali & Panini & 121.219 & 126.308 \\
\hline 22 & Arquitetura \& Construção & Abril & 120.317 & 127.604 \\
\hline 23 & Cascão & Panini & 119.729 & 124.240 \\
\hline 24 & Chico Bento & Panini & 116.939 & 123.391 \\
\hline 25 & AutoEsporte & Globo & 114.179 & 108.567 \\
\hline 26 & Galileu & Globo & 109.880 & 129.255 \\
\hline 27 & Estilo de Vida & Abril & 108.866 & 116.993 \\
\hline 28 & $\begin{array}{l}\text { Pequenas Empresas } \\
\text { Grandes Negócios }\end{array}$ & Globo & 106.343 & 107.182 \\
\hline 29 & Men's Health & Abril & 95.244 & 105.759 \\
\hline 30 & Planeta & Três & 93.430 & 121.741 \\
\hline
\end{tabular}

Fonte: IVC - Instituto Nacional de Verificação

Disponível em: <http://aner.org.br/dados-de-mercado/circulacao/>. Acesso em 12 de abr. de 2014.

\subsection{Artefatos Digitais}

$\mathrm{Na}$ tabela 2, abaixo, foi estabelecida uma tipologia de artefatos segundo quatro categorias: a) revistas digitais compostas por artefatos que preservam similaridade de estruturação de informação e formatação de uso dos artefatos impressos (azul); b) website, o próprio portal de conteúdo e artefatos constituintes, que se destacam como outra mídia (roxo); c) redes sociais (vermelho); d) outros que não se configuram como grupo (marrom). 
A tipologia está organizada com base em similaridades da entrega de conteúdo. Entretanto, os diferentes tipos de artefato se inter-relacionam, compartilhando matérias e apoiando-se mutuamente. Conteúdos da revista impressa, por exemplo, são publicados na edição para tablet, no website e, ainda, divulgados nas redes sociais. De outro modo, um vídeo publicado no youtube estará no canal de vídeos do website e na revista digital.

Tabela 2. Tipos de artefatos digitais utilizados por revistas.

\begin{tabular}{|l|l|}
\hline Aplicativo (App) iPad & App de revista para tablets iPad. \\
\hline App Tablet Android & App de revista para tablets com sistema operacional Android. \\
\hline Navegador de internet & Revistas digitais visualizadas através do navegador de internet. \\
\hline Portal de Conteúdo & O website que centraliza a presença da marca na internet. \\
\hline Canal de vídeo & Vídeos localizados em uma área específica do portal de conteúdo. \\
\hline Canal de jogos & $\begin{array}{l}\text { Também chamados newsgames, são desenvolvidos pela (ou para) a } \\
\text { revista que tem relação com o tema e/ou conteúdo da revista. } \\
\text { Localiza-se em uma área específica do portal de conteúdo. }\end{array}$ \\
\hline Podcast & Um episódio de um programa de áudio transmitido via internet. \\
\hline Redes sociais & $\begin{array}{l}\text { Facebook, Twitter, Google+, Instagram, Linkedln, Pinterest, } \\
\text { Youtube }\end{array}$ \\
\hline Apps Iphone & Aplicativos para celulares iPhone. \\
\hline App Smartphone Android & App de revista para Smartphones com sistema operacional Android. \\
\hline SMS & Conteúdo via mensagens via Short Messaging Service. \\
\hline Newsletter & Mala direta via e-mail \\
\hline
\end{tabular}

Fonte: Elaborado pelos autores, com base na pesquisa realizada.

O gráfico 1 apresenta os artefatos utilizados nas revistas segundo segundo a tipologia. Fica evidente que os websites e as redes sociais, artefatos nativos do ambiente digital, têm mais espaço que as revistas digitais. O que percebemos, confirmando a afirmação do publisher da revista Trip, é que a ideia de editora está mudando para uma produtora multimídia de conteúdo jornalístico. A revista desvincula-se do artefato impresso e passa a ser regida pela marca em seu segmento, periodicidade e público-leitor específicos.

Os aplicativos para Android e $i O S^{3}$ em geral são idênticos em conteúdo e configuração visual. A diferença está na tecnologia de desenvolvimento dos aplicativos de leitura: os Android são programados em linguagem Java e os iOS em Objective-C. No caso dos tablets, existem programas semi-automatizados que dão conta da compatibilidade. Outra diferença está na publicação dos aplicativos. Quando publicada para dispositivos com iOS os aplicativos passam por um processo revisão "baseados em um conjunto de critérios técnicos, de conteúdo e de design" (APPLE, 2014). Ao mesmo tempo que isso garante mais segurança aos aplicativos, pode ser visto como uma maneira de controlar a informação publicada. Por exemplo, a Apple possui restrições a conteúdos eróticos, impedindo a revista Playboy de ser publicada para Ipad, o que justifica a diferença numérica entre os dois artefatos.

\footnotetext{
${ }^{3}$ Sistema operacional do iPhone e do iPad.
} 


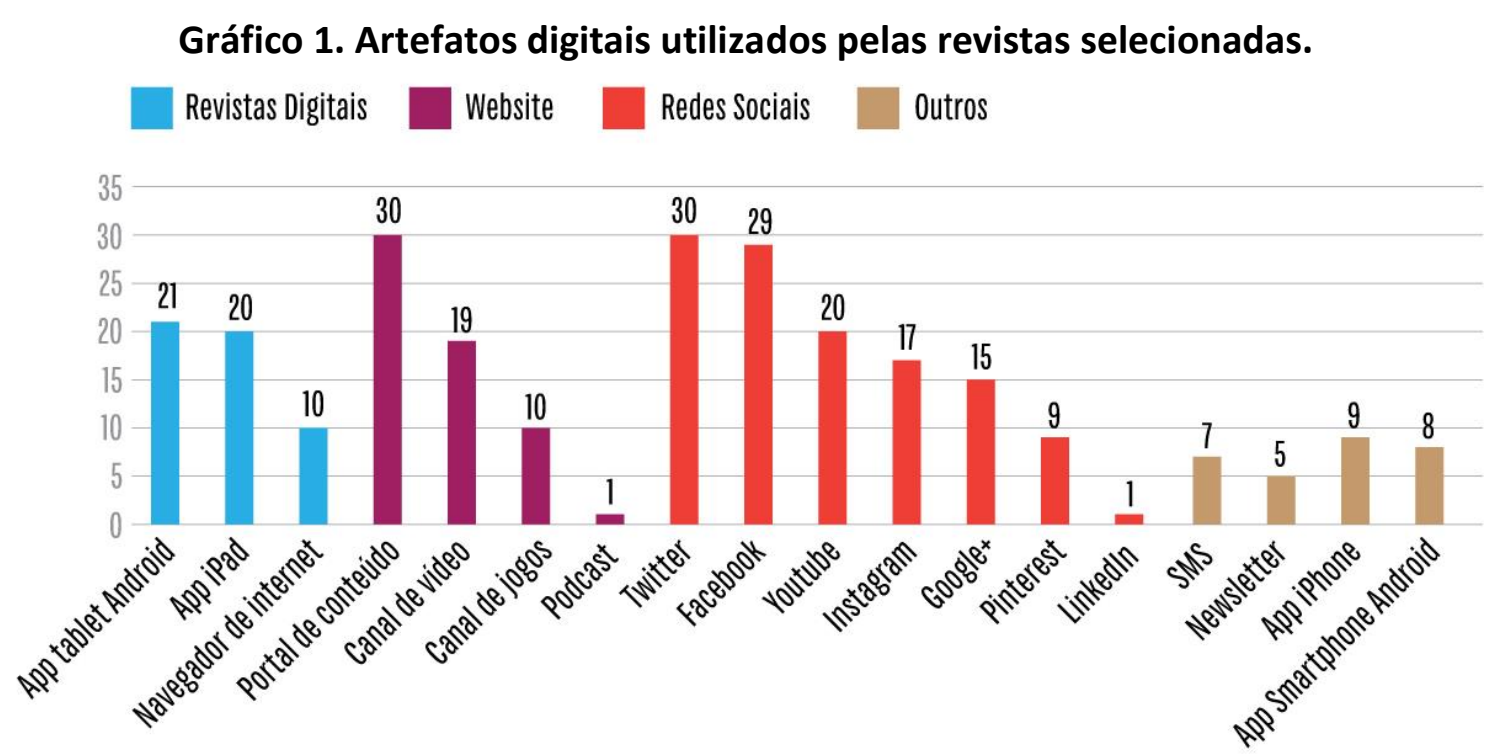

Fonte: Elaborado pelos autores com base na pesquisa realizada.

O gráfico 2 apresenta os totais de artefatos digitais, de revistas digitais e de websites, discriminados por marca. A primeira observação a partir do gráfico 2 é que não há uma diferença numérica significativa de artefatos empregados entre a revista de maior circulação e a trigésima. Registra-se uma oscilação ao longo da tabela entre 4 a 14 artefatos digitais e a média de 9,1 artefatos por marca. Salientamos que as revistas digitais e os websites no gráfico concentram o trabalho de design nas editoras, enquanto as redes sociais não demandam designers e os outros não foram investigados pela baixa expressão numérica entre as revistas.

Gráfico 2. Totais de artefatos digitais, de revistas digitais e de websites, discriminados por marca (seguindo a ordem da tabela).

\begin{tabular}{l|l} 
Revistas Digitais $\square$ Website Total de artefatos digitais
\end{tabular}

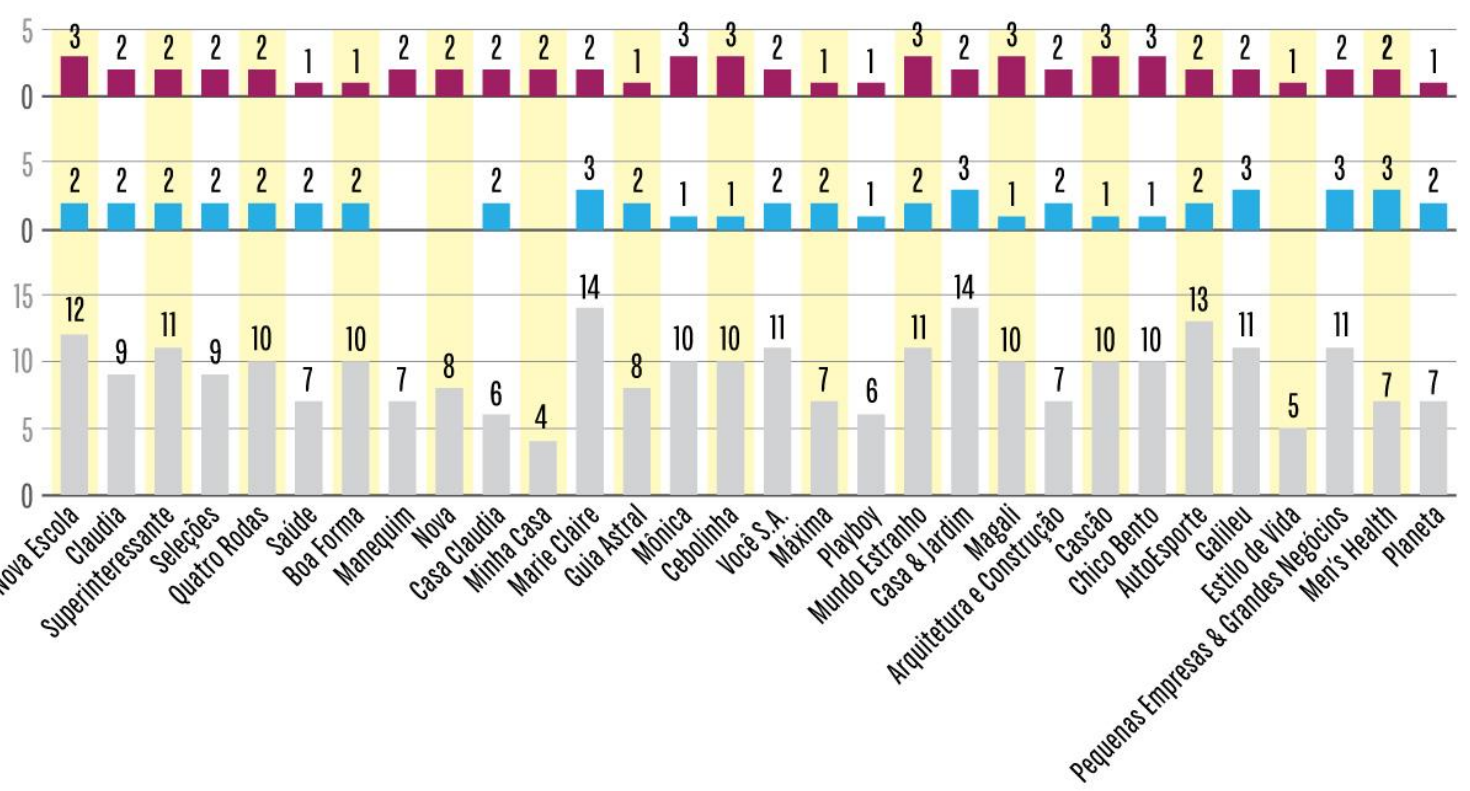

Fonte: Elaborado pelos autores com base na pesquisa realizada. 


\subsection{Redações e núcleos digitais}

Além do levantamento dos artefatos digitais, foram averiguadas as funções declaradas nos expedientes das revistas selecionadas, com o intuito de estabelecer uma aproximação preliminar do lugar ocupado pelo design nas atuais equipes de edição de revista.

Cada novo artefato lançado por uma marca demanda remodelação da estrutura de trabalho. A criação de núcleos específicos para atender mídias digitais traz ao jornalismo de revista novas carreiras, como as de analista de redes sociais, animador, desenvolvedor, diretor de estratégia digital, editor de tablet, webdesigner, webmaster, entre outras.

Entretanto, o levantamento a partir do expediente não possibilita identificar exatamente as funções cobertas pelas novas denominações profissionais. Nos núcleos digitais podemos perceber uma falta de padronização das denominações no contexto geral do universo de análise, em contraste com a predominância de funções consolidadas nas redações: diretor de redação, editor, repórter, responsáveis pelos textos; e diretor de arte, editor de arte e designer, responsáveis pelo design.

Os núcleos digitais tendem a manter essa estrutura organizacional valendo-se de denominações que fazem alguma menção as mídias digitais referentes à função, ao meio de comunicação ou perfil. Listamos segundo a hierarquia estrutural: a) diretivas diretor criativo, diretor de inovação digital, diretor de convergências; coordenador de interfaces digitais; gerente de interface digital, gerente de tecnologia digital; b) editoriais - editor de mídias sociais, editor de mídias digitais; c) específicas ou subordinadas - analista de redes sociais; animador; desenvolvedor; produtor multimídia; webdesigner; e webmaster.

Quando a editora Globo denomina como diretor de inovação digital o responsável pelo Núcleo de Inovação Digital, está enfatizando o caráter de incerteza e experimentação frente ao campo recente que vem sendo explorando. Mesmo que esse diretor promova inovações, primordialmente sua função é a de coordenar o núcleo digital. No mesmo núcleo existe um diretor de convergências, referindo-se ao fenômeno ao qual Jenkins se refere como convergência de cultura, que tornou-se um termo corrente na área da comunicação. Eventualmente esses nomes mais parecem estar alinhados aos objetivos de marketing das editoras, demonstrando-se atuais e acompanhando tendências, do que propostos para identificar funções de modo descritivo. Esta estratégia de afirmação de uma nova condição editorial se verifica também no oferecimento de produtos e serviços. As revistas digitais para tablets, por exemplo, apresentam circulação ainda baixa e não cobrem a queda da circulação das revistas impressas. Todavia sua presença também é estratégica: segundo pesquisa do IVC, revistas que não têm edição digital apresentaram queda de 3\% a 4,4\% em 2013 em relação ao ano anterior (A CIRCULAÇÃO, 2014). Marcar presença por meio de mídias digitais, portanto, além de oferecer mais um serviço de entrega de conteúdo também serve ao objetivo de valorização da marca.

A maior parte dos expedientes não faz menção às funções que atenderiam os respectivos artefatos digitais. Apesar dos canais de vídeos estarem presentes em $63 \%$ dos portais de conteúdo, nenhuma das revistas declarou em seu expediente qualquer função relacionada à produção de vídeos. Uma explicação para a questão se evidencia no caso da revista Você S.A., integrante do núcleo digital e portal Exame.com, que recorre ao núcleo de vídeos da revista Exame. 
Mas há, também, outras explicações. Quando há um grande número de artefatos midiáticos mas não são identificadas as funções respectivas, justifica-se a conjectura de que se busca uma redução de custos. Isso pode ser observado a partir do que está explicitado nos expedientes. Entre as estratégias mais utilizadas podemos apontar: (1) acúmulo de funções por profissional; (2) compartilhamento de profissionais entre núcleos e redações; (3) mão de obra ainda sem registro profissional; (4) terceirização para situações específicas, evitando vínculos trabalhistas que resultem em encargos trabalhistas.

No primeiro caso, por exemplo, os designers que integram as redações passariam a editar tanto a edição impressa quanto a edição para tablet. No segundo caso, temos os núcleos digitais, responsáveis pelo design dos portais de conteúdos, gerenciamento de redes sociais, entre outros. O núcleo e portal $M$ de mulher congrega as revistas Claudia, Saúde, Manequim, Nova, Máxima e Estilo de vida. No terceiro caso, verificamos o emprego de estagiários em funções que deveriam ser exercidas por profissionais. Por exemplo, na revista Men's Health são os estagiários que cumprem a função de designer e de webmaster; já na revista Casa Claudia eles cuidam das redes sociais. No quarto caso observamos a terceirização. O expediente da Playboy registra um número de colaboradores (29) por edição maior que o tamanho da redação (9) entre os quais profissionais de arte, ilustração e produção de moda. Outro caso de terceirização acontece na revista Planeta: a criação e manutenção dos portais de conteúdos das revistas e monitoramento das mídias sociais são terceirizados para uma agência digital.

Outro dado significativo é o de que as revistas impressas empregam diretamente mais profissionais que todas as mídias digitais. O somatório de todas redações pesquisadas é quase o dobro de profissionais que os núcleos digitais: 305 e 161 , respectivamente. Se considerado apenas os designers, a diferença passa para o triplo entre aqueles que trabalham nas redações (58) e nos núcleos digitais (17). O que se justifica porque muitos profissionais atuam em núcleos digitais que atendem mais de uma revista.

\subsection{Designer: denominações e atribuições}

Para se referir, de modo geral, ao design existe o recurso a categorizações correntes na área editorial - entre as quais aquelas de diretor de arte, vinda da propaganda, de editor de arte, do jornalismo, e de designer, que designa apenas o diagramador. Tradicionalmente o diretor de arte é o responsável pelo projeto gráfico da revista; o editor de arte tem a função de gerenciar o trabalho dos designers, de acompanhar o fluxo de envio de textos da edição para a arte e de fechamento dos arquivos para envio da gráfica; e o designer que trabalha a diagramação é responsável pela diagramação da revista segundo orientações do diretor e do editor de arte, assim como das direções geral e setoriais da revista.

Estas atribuições não são fechadas e, apesar de recorrentes, variam de redação para redação de acordo com o perfil daqueles que gerenciam a equipe e das demandas de trabalho. Com a queda de circulação das revistas impressas, as editoras reduziram o número de profissionais nas redações, tornando estas diferenças mais tênues.

Sabemos, de modo não sistemático, que o cargo do diretor de arte tende a ser ocupado por designers de formação. Entretanto, o projeto gráfico em revistas tem uma de suas origens no campo publicitário, o que explica o vínculo terminológico do 
meio. Foram os diretores de arte do campo publicitário norte-americano que popularizaram a expressão design gráfico para o layout de revistas a partir da década de 1930 (BRAGA, 2011, p. 12). Ironicamente, na hierarquia editorial o design corresponde à função mais subalterna, referindo-se ao trabalho de criação com ênfase técnica e executiva, enquanto ao diretor de arte caberiam as diretrizes projetuais do artefato.

A seguir serão destacados aspectos da apresentação das equipes em relação à presença do designer e suas relações entre as demais funções.

Antes restrito às atribuições gráficas, como as de diretor de arte, editor de arte, diagramador, ilustrador e infografista, hoje há espaço para outras habilitações: designer de interação, designer audiovisual e designer de jogos. A revista Casa \& Jardim, por exemplo, declara em seu expediente um coordenador de interfaces digitais, já na Superinteressante consta um profissional responsável pela animação.

O designer destaca-se tanto nas redações quanto nos núcleos digitais como podemos observar nas tabelas 3 e 4 . Nas redações, as denominações de designer, editor de arte e diretor de arte estão entre as cinco mais recorrentes nos expedientes das revistas em relação a outras denominações, assim como nos núcleos digitais o editor de arte, o designer e o webdesigner ${ }^{4}$.

Tabela 3 - Denominações mais recorrentes nos expedientes das redações

\begin{tabular}{llllll}
\hline & Designer & Editor & $\begin{array}{l}\text { Diretor } \\
\text { de redação }\end{array}$ & $\begin{array}{l}\text { Editor de } \\
\text { arte }\end{array}$ & $\begin{array}{l}\text { Diretor de } \\
\text { arte }\end{array}$ \\
\hline Ocorrência & $90 \%$ & $80 \%$ & $63 \%$ & $57 \%$ & $50 \%$ \\
\hline
\end{tabular}

Fonte: Elaborado pelos autores, com base na pesquisa realizada.

Tabela 4 - Denominações mais recorrentes nos expedientes dos núcleos digitais

\begin{tabular}{llllll}
\hline Editor Repórter & Webmaster & $\begin{array}{l}\text { Editor assistente, } \\
\text { Editor arte, designer e } \\
\text { webdesigner }\end{array}$ & Estagiários \\
\hline Ocorrência & $86 \%$ & $57 \%$ & $43 \%$ & $36 \%$ & $29 \%$ \\
\hline
\end{tabular}

Fonte: Elaborado pelos autores, com base na pesquisa realizada.

O menor número de diretores de arte em relação a designers nas redações e a ausência desta função nos núcleos digitais podem indicar uma tendência da sua substituição por outras funções que atendam às necessidades e protocolos do meio (tabela 3). Nas mídias digitais, em geral as categorias experiência do usuário, interface, interação e web, são mais corriqueiras do que direção de arte.

Nas redações o termo diretor de arte é substituído em três revistas: na revista Autoesporte a titulação é atualizada para atender as mídias digitais passando a ser diretor de design multiplataforma; na revista Casa Claudia a função é chamada de coordenadora de arte; e na revista Planeta há uma inversão das funções, o diretor de arte está abaixo de um supervisor de arte e não constam editores de arte e designers. A ausência de diretores de arte nas revistas que integram o núcleo digital e portal $M$

${ }^{4}$ Foram encontradas as duas denominações dentro dos núcleos digitais. Especulamos que podem não indicar funções diferentes, mas inconsistências nominativas. 
de Mulher justifica-se na presença de uma diretora geral para o núcleo todo denominada diretora criativa.

\section{CONSIDERAÇÕES FINAIS}

A partir desta pesquisa foi possível observarmos três situações que vêm acontecendo face às reestruturações das editoras para acomodar os artefatos digitais. A primeira, a partir da visualização do amplo espectro de artefatos digitais organizados segundo tipologia proposta, indica a tendência de editoras tornarem-se produtoras de conteúdo multimídia, direcionadas pela identidade de marca e não mais especificamente pelo vínculo com o artefato impresso - apesar desse ainda ser o principal produto.

Se na revista tradicional o engajamento com o público era feito através do conteúdo e da identidade visual da revista, no meio digital existem ainda outras maneiras de estabelecer essa aproximação, que envolvem a fragmentação, dispersão e simultaneidade desses conteúdos entre artefatos impressos e digitais. O resultado é uma ampliação do número de funções, pedindo reformulações/otimizações dos quadros funcionais.

De acordo com a segunda, ao compararmos os artefatos digitais com as funções declaradas nos expedientes identificamos os modos de organização dos núcleos para gerenciar esses artefatos. E também uma diferenciação quanto à denominação de funções nos núcleos digitais, caracterizando tanto uma presença ainda não consolidada quanto uma intenção de se apresentar de um modo tecnicamente atualizado.

A relação intensa com o público leitor e a constante atualização desse vínculo são potencializadas pelas mídias digitais. A crescente migração de leitores que buscam informações nas mídias digitais e a constante queda na tiragem dos impressos são sintomas das mudanças tecnológicas, econômicas e culturais que impactam a área da comunicação. E essa dinâmica passa a fazer parte da operação das editoras, levando-as a reestruturações em seus modelos de negócios e em seus quadros funcionais.

Por fim, a terceira diz respeito à posição dos designers nas redações e núcleos digitais. Esses profissionais destacam-se entre os mais presentes nas duas áreas, reforçando a sua importância para as editoras. Ainda que não revelados nos expedientes, podemos citar a formação de novas equipes para auxiliar a produção de artefatos digitais. A editora Abril possui uma equipe formada por designers exclusivamente para edição dos tablets, assim como uma equipe de teste, suporte e treinamento de revistas digitais também formada por designers e programadores.

Outro aspecto observado foi um menor número de diretores de arte em relação a designers nas redações; e também a ausência da função nos núcleos digitais, que recorrem a denominações genéricas ou mais adequadas a um cenário multimídia. Cabe ressaltar que somente a partir do expediente não é possível precisar os antecedentes e nem as causas dessa situação, cabendo investigação mais aprofundada valendo-se de outros métodos de pesquisa.

Independente do estado econômico e organizacional das editoras, o designer é parte fundamental tanto para as redações quanto para os núcleos digitais. Quando essas mudanças colocam em xeque a própria noção tradicional de revista - que é ressignificada em um contexto de caráter plural - isso demonstra, numa visão positiva, 
um novo campo de possibilidades que se abre tanto para novos equacionamentos da forma revista, quanto para novos desenhos de suas equipes de realização.

\section{REFERÊNCIAS}

A CIRCULAÇÃO de revistas digitais cresceu 5,8\% no segundo semestre aponta IVC. Jornal Folha de S. Paulo. São Paulo, 20 de abr. de 2014. Disponível em:

<http://www1.folha.uol.com.br/mercado/2014/03/1428475-circulacao-de-revistasdigitais-cresceu-58-no-segundo-semestre-aponta-ivc.shtml>. Acesso em 12 de ago. 2014.

APPLE Developer. Disponível em: <https://developer.apple.com/ios7/ >. Acesso em 27 de abr. de 2014.

ARAÚJO, Silvia Amélia de. Rotinas produtivas em revista: padrões e transformações no fazer de uma publicação segmentada. In: TAVARES, Frederico de Mello B. ; SCHWAAB, Tavares (Orgs.). A revista e seu jornalismo. Porto Alegre: Penso, 2013.

BRAGA, Marcos da Costa da. O papel Social do Design gráfico. São Paulo: Editora Senac, 2011.

COHN, Sergio. Revistas de invenção: 100 revistas de cultura do modernismo ao século XXI. Rio de Janeiro: Beco do Azougue, 2011.

GRUSZYNSKI, Ana C.; CALZA, Márlon U.. Projeto gráfico: a forma de um conceito editorial. In: TAVARES, Frederico de Mello B. ; SCHWAAB, Tavares (Orgs.). A revista e seu jornalismo. Porto Alegre: Penso, 2013.

JENKINS, Henry. Convergence culture: Where Old and New Media Collide. New York: New York University Press, 2006.

MARTINS, Ana Luiza. Revista em revista. São Paulo: EDUSP, 2001.

PARENTE, Edianez. Mobilidade em Pauta. In: Especial Revistas: mobile magazines. São Paulo: Jornal Meio \& Mensagem, set. 2013.

Edianez. O choque do futuro: comportamento e customizadas. In: Especial Revistas: mobile magazines. São Paulo: Jornal Meio \& Mensagem, set. 2013.

STORCH, Laura. Revista e leitura: Sujeitos e interação. In: TAVARES, Frederico de Mello B. ; SCHWAAB, Tavares (Orgs.). A revista e seu jornalismo. Porto Alegre: Penso, 2013.

TAVARES, Frederico de Mello B.; SCHWAAB, Reges. Revista e comunicação: percursos, lógicas e circuitos In: TAVARES, Frederico de Mello B.; SCHWAAB, Tavares (Orgs.). A revista e seu jornalismo. Porto Alegre: Penso, 2013.

VOGEL, Daisi. Revista e contemporaneidade: imagens, montagens e suas anacronias. In: TAVARES, Frederico de Mello B.; SCHWAAB, Tavares (Orgs.). A revista e seu jornalismo. Porto Alegre: Penso, 2013.

WERNECK, Humberto et al. Revistas no Brasil. São Paulo: Editora Abril, 2000. 